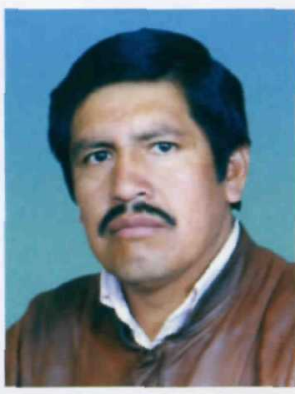

Recopilado por: Ing. Agr. Marcelo Jimbo G.

El éxito del aprendizaje depende sobre todo de tres factores: Ia inteligencia del aprendiz (o sea su capacidad de aprendizaje); el método, según el cual se aprende; y la motivación que incita a estudiar. El tercer factor es el más importante.

2. Todas las informaciones captadas reciben un tinte emocional en dos regiones del cerebro, el sistema límbico y el tálamo. Por ello un profesor debería esforzarse por presentar la materia de tal modo que se generen sentimientos lo más positivos posibles, en el aprendiz. Cuando el estudiar está asociado a sentimientos desagradables, el aprendiz no retiene nada.

3. La red fibrosa que se forma durante los primeros tres meses de vida, con cerca de 15000000 neuronas cerebrales, aproximadamente, genera un modelo básico de cuya estructura depende el cómo aprenderá un individuo más tarde (memoria más visual, auditiva, etc.). Por ello habría que elegir los medios de enseñanza para ofrecer a todos los tipos de aprendices una forma óptima de comprensión de la materia.

4. Si se quiere que los grupos trabajen eficazmente, hay que cumplir las condiciones siguientes:

- el grupo debería ser suficientemente pequeño para que todos tengan ánimo y oportunidad para hablar;

- el grupo debería ser suficientemen-

\section{La enseñanza y el aprendizaje}

te amplio para que estén representados conocimientos u opiniones diferentes;

- todos los participantes deberían pertenecer al mismo rango;

- Ia dirección de la discusión debería ser asumida alternativamente, para crear interdependencia;

- todos los participantes deben estar preparados y motivados.

- Se requiere del asesoramiento contínuo del facilitador.

5. La memoria, inmediata, de plazo ultracorto no almacena informaciones. Los impulsos eléctricos circulan en nuestra red de fibras cerebrales. Este proceso dura entre 10 y 20 segundos.

6. Todo lo que queremos aprender, para finalmente quedarse grabado en la memoria a largo plazo, mediante las moléculas de proteína, deberá transcurrir por el mismo itinerario: memoria inmediata, memoria a corto plazo, memoria a largo plazo. No existe otra forma de entrada a la memoria.

7 Para poner a funcionar el mecanismo memoria inmediata/memoria a corto plazo/memoria a largo plazo, se recomienda repetir varias veces la misma información durante el transcurso de la enseñanza.

8. Para hacer más fácil o acelerar el paso de una información a la memoria a largo plazo, es recomendable presentar la materia en un ambiente de eustress (influencia hormonal) y dividirla de forma tal que se generen muchas asociaciones (conexiones con el modelo básico) en el aprendiz.

9. Para evitar retrasos en la entrada a la memoria a largo plazo, se recomienda no ofrecer, durante un espacio de tiempo demasiado reducido, demasiadas informaciones de contenidos distintos; y también, evitar los ambientes de distress, porque el distress origina un bloqueo hormonal en la sinapsis (centros de conexión).

10. Hay tres tipos de aprendizaje humano:

- el condicionamiento clásico;

- el condicionamiento operativo;

- el aprendizaje por razonamiento. 


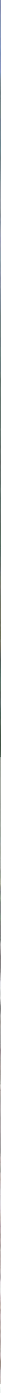

11. Cuanto más dividida está la materia y cuantas más leyes tangibles contenga, tanto menos olvidada quedará.

12. Al aprender materias con contenidos semejantes, una tras otra, se perturban mutuamente (fenómeno de la interferencia). Por ello habría que cambiar frecuentemente de materias.

13. Se combate el cansancio durante el aprendizaje mediante frecuentes intervalos breves. Asimismo el aprendizaje activo, en el que el participante tiene que hacer algo, impide un cansancio rápido. Regla práctica: hay que incluir un intervalo breve de 20 en 20 minutos. Hay que ofrecer temas antitéticos. Hay que utilizar a menudo el aprendizaje activo.

14. El profesor que tiene éxito a la larga, corresponde a un perfil de cualidades cuyos factores más importantes son los siguientes: autoridad natural, ciencia o conocimientos superiores, capacidad psicológica de ponerse en el lugar del otro y entusiasmo.

15. Los refuerzos (elogios bien dosificados y en el momento oportuno) son recomendados, y por si mismos, no implican necesariamente un efecto de aprendizaje positivo; solo tienen un efecto motivador positivo al coincidir con las necesidades de una persona.

16. La enseñanza solo conduce a un éxito seguro si los nuevos modelos de comportamiento son adquiridos y ejercitados mediante el aprendizaje activo.

17 A cada materia debe adaptarse un tipo de enseñanza. Esto sig- nifica que la didáctica debería adecuarse, en su dinámica, a la esencia de la materia.

18. Los adultos quieren que se les exija mucho. Cuanto más se les exige, tanto más fuerte es la vivencia del éxito. Por ello debería llevarse a los estudiantes hasta los límites de sus capacidades y no situar las realizaciones a un nivel demasiado bajo.

19. Siempre que resulte posible, la enseñanza debería ser estructurada de manera que los participantes sientan agrado. El profesor que suscita la curiosidad, promueve la variedad y enriquece la enseñanza con humor, consigue la mejor motivación para que los participantes aprendan.

20. El profesor debería elegir un estilo que corresponda tanto a los objetivos pretendidos, como a la composición del grupo. En caso de duda, es preferible que sea un poco más autoritario que demasiado filántropo. Demasiada libertad resulta siempre interpretada como una debilidad y es inmediatamente aprovechada por el grupo.

21. Cuando el grupo tiene dificultades de integración, el maestro tiene que limitarse a una función de moderador. Puede ayudar bajo la forma de consejos, pero nunca debe de solucionar él mismo los problemas del grupo.

22. El profesor debe cuidar que la resonancia del grupo, frente a los distintos miembros, sea preponderantemente positiva. Debería otorgar alabanzas que equilibren la falta de elogios por parte del grupo, cuando éste no reconoce los buenos resultados de un participante. 